\title{
Exploring Teachers Perceptions of Web-Based Learning Tools
}

\author{
Robin Kay, Liesel Knaack, and Diana Petrarca \\ University of Ontario Institute of Technology, \\ Oshawa, Ontario, Canada
}

robin.kay@uoit.ca; liesel.knaack@uoit.ca; diana.petrarca@uoit.ca

\begin{abstract}
Over the past 8 to 10 years, web-based learning tools (WBLT s), also known as learning objects, have been evaluated and received positively by higher education students. However, little research has been done examining teachers perceptions of these tools, particularly in middle and secondary school environments. The purpose of the current study was to analyse teacher perceptions of the use of WBLT in middle and secondary school classrooms. Data collected from the Learning Object Scale for Teachers (LOES-T) showed moderate to good reliability and demonstrated construct and convergent validity. Overall, most teachers rated WBLT s as easy-to-use and engaging for students. They also reported that WBLT s promoted successful learning. A number ofteachers noted that significant time was spent searching for appropriate WBLT s and preparing lessons. Technological problems related to WBLT s were not reported oft en and focussed mostly on Internet speed. The main suggestion offered by teachers was to be prepared to spend time selecting, testing, and preparing the materials in order to ensure successful use of WBLT s.
\end{abstract}

Keywords: evaluate, assess, usability, scale, secondary school, WBLT s, web-based learning tools

\section{Literature Review}

In the past 10 years, a concerted effort has been made to increase the presence of technology in K-12 classrooms. Many countries report average student-to-computer ratios at about 5 to 1 and Internet access in schools above 90\% (Compt on \& Harwood, 2003; McRobbie, Ginns, \& Stein, 2000; Plante \& Beattie, 2004; US Department of Education, National Center for Education Statistics, 2002). However, a number of researchers have argued that the mass infusion of technology in the classroom has had a minor or negative impact on student learning (e.g., Cuban, 2001; Roberston, 2003; Russell, Bebell, O'Dwyer, \& O'Connor, 2003; Waxman, Connell, \& Gray, 2002). Part of the problem stems from a considerable list of barriers that a number of teachers face, even when computers are available. These barriers include a lack of time (Eifler, Greene, \& Carroll,

Material published as part of this publication, either on-line or in print, is copyrighted by the Informing Science Institute. Permission to make digital or paper copy ofpart or all of these works for personal or classroomuse is granted without fee provided that the copies are not made or distributed for profit or commercial advantage AND that copies 1) bear this notice in full and 2) give the full citation on the first page. It is permissible to abstract these works so long as credit is given. To copy in all other cases orto republish or to post on a serveror to redistribute to lists requires specific permission and payment ofa fee. Contact Publisher@, InformingScience.org to request redistribution permission. 2001; Wepner, Ziomek, \& Tao, 2003), limited technological skill (Eifler et al, 2001; Strudler, Archambault, Bendixen, Anderson, \& Weiss, 2003; Thompson, Schmidt, \& Davis, 2003), fear of technology (Bullock, 2004; Doering, Hughes, \& Huffman, 2003), and a clear lack of understanding about how to integrate technology into teaching (Cuban, 2001). In addition, it is unclear how student-to-computer ratios translate into 
actual classroom use, as there are still reports of limited access to technology (e.g., Bart lett, 2002; Brush et al., 2003; Russell et al., 2003).

\section{The Role of WBLTs}

Web-based learning tools (WBLT s), also referred to as learning objects in the literature, are defined in this study as "interactive web-based tools that support learning by enhancing, amplifying, and guiding the cognitive processes of learners" (Agostinho, Bennett, Lockyer, \& Harper, 2004; Butson, 2003; McGreal, 2004; Parrish, 2004; Wiley, et al. 2004). WBLT s offer two not eworthy features that can reduce the impact of potential obstacles teachers face when using technology. First, typical WBLT s are designed to focus on specific concepts, making them easy to learn, easy to use, and more attract ive to busy educators who have little time to learn more complex, advanced software packages (Gadanidis, Gadanidis, \& Schindler, 2003). Ease of use also makes WBLT s more palatable to teachers who are apprehensive about using technology (Kay, Knaack, \& Muirhead, in press).

Second, a wide range of WBLT s exist including drill-and-practice assessment tools (Adams, Lubega, Walmsley, \& Williams, 2004) or tut orials (Nurmi \& Jaakkola, 2006), video case st udies or supports (Kenny, Andrews, Vignola, Schilz, \& Covert, 1999; MacDonald et al., 2005), general web-ba sed multimedia resources (Van Zele, Vandaele, Botteldooren, \& Lenaerts, 2003), and selfcontained interactive tools in a specific content area (Bradley \& Boyle, 2004; Cochrane, 2005). Furthermore, in contrast to other leaming technologies burdened with implementation challenges and costs, WBLT s are readily accessible over the Internet and teachers need not worry about excessive costs or not having the latest version (Wiley, 2000). It is speculated that the broad selection of readily accessible WBLT s will make it easier for teachers to integrate WBLT s into a classroom environment.

In summary, barriers to using technology reported by teachers such as time, limited skill, fear of technology, and limited access to technology are partially addressed by easy-to-use WBLT s that are readily accessible in a wide variety of pedagogical formats.

\section{WBLT Research in Middle and Secondary School Classrooms}

Exist ing WBLT or learning object research is limited to the domain of higher education. Out of the 41 empirical studies reviewed for this paper, 29 (70\%) focussed on WBLT use in higher education, whereas only eight (20\%) examined WBLT use in middle or secondary school classrooms (Brush \& Saye, 2001; Ilomäki, Lakkala, \& Paavola, 2006; Kay \& Knaack, 2007a; Kong \& Kwok, 2005; Liu \& Bera, 2005; Lopez-Morteo \& Lopez, 2007; McCormick \& Li, 2006; Nurmi \& Jaakkola, 2006).

Four studies examined middle school students' use of WBLTs. Kong \& Kwok (2005) looked at nine-year-old students' independent use of WBLT s for 15-20 hours while attempting to learn about fractions. Students who used WBLT s significantly outperformed students who did not use WBLT s. Ilomäki et al. (2006) examined 11 and 12 year old students using WBLT s to study eating habits. Teachers and students did not assess the effectiveness of the five week, WBLT unit, but the pedagogical strat egies used by the instructors were described in detail. Liu \& Bera (2005) examined middle school students' use patterns with respect to a range of WBLT s. Eighty-two percent of the students generated successful solutions using WBLT s. Finally, Nurmi \& Jaakkola (2006) reported that interactive, simulation-based WBLT s produced significantly better results than drill-and practice WBLTs.

Five studies looked at the use of WBLT s in the secondary school classroom. Brush \& Saye (2001) reported that students tended to look at superficial content in a WBLT when left to their own devices and that more active guidance and structure was needed when using information- 
based WBLTs. Ilomäki et al. (2006) explored the pedagogical affordances of WBLTs in three areas: nutrition, sense of the brain, and multiple intelligences. Kay \& Knaack (2007b) used a comprehensive assessment tool to evaluate the use of WBLT s and found that overall usefulness, clear instructions, organized layout, and good theme/motivation were particularly import ant to students. Lopez-Morteo \& Lopez (2007) reported that students perceived interactive, recreationbased, collaborative WBLT s positively.

Finally, McCormick \& Li (2006) completed an extensive study examining the attitudes of 770 secondary schools teachers from six different European countries toward using WBLT s from the CELEBRATE collection. Overall, 70\% of theteachers thought WBLT s were useful. Just over half the teachers felt WBLT s were well designed, although this was clearly dependent on the type of WBLT chosen. Over 50\% of teachers experienced Internet problems while using WBLT s. In addition, roughly $60 \%$ of all instructors thought WBLT s improved their teaching and felt that students were more engaged.

Overall, WBLT-use research is positive, albeit somewhat ad hoc and inconsistent in data collection strat egies. Two studies gathered user performance data, (Kong \& Kwok, 2005; Nurmi \& Jaakkola, 2006), four studies collected descriptive data (Brush \& Saye, 2001; Ilomäki et al., 2006; Liu \& Bera, 2005; McCormick \& Li, 2006), one study implemented a formal survey (Kay \& Knaack, 2007a, 2007b), and one study accumulated anecdotal reports (Lopez-Morteo \& Lopez, 2007). With the exception of McCormick and Li's (2006) paper, all eight previous studies looked at student perceptions exclusively; teacher impressions of how well the WBLT s worked were not examined.

\section{Purpose}

The purpose of this study was to explore teacher perceptions of the use of WBLTs in middle and secondary school classrooms. Specifically, the following five research questions were addressed:

1. How do middle and secondary school teachers use WBLT s?

2. What are middle and secondary school teachers' perceptions of WBLT s with respect to learning value, usability, and engagement?

3. How do middle and secondary teachers' perspectives of learning, usability, and engagement compare with students' perceptions of the same three constructs?

4. How do middle and secondary teachers' perspectives of learning, usability, and engagement correlate with student learning performance?

5. What challenges do middle and secondary school teachers experience when using WBLT s?

\section{Method}

\section{Overview}

At least five key observations are worth noting with respect to methods used to evaluate WBLT s. First, the majority of evaluation papers focus on only one WBLT (Adams et al., 2004; Bradley \& Boyle, 2004; Kenny et al., 1999; Krauss \& Ally, 2005; MacDonald et al., 2005). It is difficult to determine whether the evaluation tools used for a single WBLT generalize to the full range of WBLT s that are available.

Second, sample populations tested in many studies have been noticeably small and poorly described (e.g., Adams et al., 2004; Cochrane, 2005; Krauss \& Ally, 2005; MacDonald et al., 2005; Van Zele et al., 2003) making it challenging to extend any conclusions to a larger population. 
Third, while many evaluation studies reported that students benefited from using WBLTs, the evidence is based on loosely designed assessment tools with no validity or reliability (Bradley \& Boyle, 2004; Howard-Rose \& Harrigan, 2003; Kenny et al., 1999; Krauss \& Ally, 2005; LopezMorteo \& Lopez, 2007; Schoner, Buzza, Harrigan, \& Strampel, 2005; Vacik, Wolfslehner, Spork, \& Kortschak, 2006; Van Zele et al., 2003; Vargo, Nesbit, Belfer, \& Archambault, 2002). Very few evaluation studies (e.g., Kay \& Knaack, 2007a, 2007b; Kenny et al., 1999; Van Zele et al., 2003 ) use formal statistics. The lack of reliability and validity of evaluation tools combined with an absence of statistical rigour reduce confidence in the results presented to date.

Fourth, very little has been written about the actual use of WBLT s from a classroom teacher's perspective. Only two studies (Kay \& Knaack, 2007a; McCormick \& Li, 2006) out of the 41 reviewed for this paper evaluated the use of WBLTs with a sample consisting of mult iple teachers.

Finally, a promising trend in WBLT evaluation research is the inclusion of learning performance measures (e.g., Adams et al., 2004; Bradley \& Boyle, 2004; Docherty, Hoy, Topp, \& Trinder, 2005; MacDonald et al., 2005; Nurmi \& Jaakola, 2006). Until recently, there has been little evidence to support the usefulness or pedagogical impact of WBLTs. The next step is to refine current evaluation tools to determine specific qualities of WBLT s that influence performance.

In summary, previous methods used to evaluate WBLT s are limited with respect to sample size, representative populations, reliability and validity of dat a collection tools, and the use of formal statistics. Recent evaluation efforts to incorporate learning performance should be encouraged in order to advance knowledge of WBLT features that may influence learning.

The following steps were taken to address the methodical concerns noted above:

1. a relatively large, diverse, sample of teachers was examined;

2. reliability and validity est imates were calculated ;

3. formal statistics were used where applicable;

4. both qualitative and quant it at ive data were collected;

5. specific WBLT s features based on instructional design research were examined; and

6. a range of WBLT s was tested.

\section{Sample}

\section{Teachers}

The teacher sample consisted of 33 teachers ( 12 males, 21 females) and 64 classrooms (a number of teachers used WBLT s more than once). These teachers had 0.5 to 33 years ofteaching experience $(M=9.0, S D=8.2)$ and came from both middle $(\mathrm{n}=6)$ and secondary schools $(\mathrm{n}=27)$. Most teachers taught math $(n=16)$ or science $(n=15)$. A majority of the teachers rated their ability to use computers as strong or very strong $(n=25)$ and their attitude toward using computers as positive or very positive $(n=29)$, although only six teachers used computers in their classrooms more than once a month.

\section{Students}

The student sample consisted of 1113 students ( 588 males, 525 females), 10 to 22 years of age ( $M$ $=15.5, S D=2.1)$, from both middle $(\mathrm{n}=263)$ and secondary schools $(\mathrm{n}=850)$. The population base spanned three separate boards of education, six middle schools, 15 secondary schools, and 33 different classrooms. The students were selected through convenience sampling and had to obtain written permission from their parents to participate. 


\section{WBLTs}

In order to simulate a real classroom as much as possible, teachers selected any WBLT they deemed appropriate for their curriculum. As a starting point, they were introduced to a wide range of WBLT s located at the LORDEC website

(http://www.education.uoit.ca/lordec/collections.html). Sixty percent of the teachers selected WBLT s from the LORDEC repository; the remaining teachers used Google to locate curriculum appropriate WBLT s. A total of 48 unique WBLTs were selected addressing concepts in biology, Canadian hist ory, chemistry, general science, geography, mathematics, and physics (see Appendix A for the full list).

\section{Procedure}

Teachers from three boards of education were invited by the school board technology coordinator to participate in this study. Teachers attended a half-day training session in November 2006 to learn how to choose, use, and assess WBLT s (see http://www.education.uoit.ca/lordec/lo use.html for more details on thetraining provided). They were then asked to use at least one WBLT in their classrooms by April 2007 of the following year. All students in a given teacher's class used the WBLT that the teacher selected; however, only those students with signed parental permission forms were permitted to fill in an anonymous, online survey about their use of the WBLT. In addition, students completed a pre- and post-test based on the content of the WBLT. Lastly, email support for teachers was available for the duration of the study. Because student surveys were anonymous, it was impossible to attain an accurate assessment of response rate.

\section{Data Sources}

\section{Teacher survey}

To establish the cont ext of use, teachers were asked (a) how long it took them to find and integrate WBLT s into their classroom, (b) their purpose for using the WBLT (e.g., motivate students, teach a new concept, review, supplement ing a lesson), and (c) strat egies they used to int egrate WBLT s (e.g., demonstration, providing a set of guiding questions, let student explore, discussion after WBLT).

In addition, after using a WBLT, each teacher completed the Learning Object Evaluation Scale for Teachers (LOES-T) in Appendix B. The quantitative items of this 7-point Likert scale examined perceptions of student learning (leaming construct), usability of the WBLT (usability construct), and student engagement with the WBLT (engagement construct). The selection of these constructs was based on a detailed review of the learning object literat ure over the past 10 years (Kay \& Knaack, 2005, 2007b, in press). Finally, teachers responded to four open-ended questions focussing on overall impact on learning, technical problems, and suggestions for fut ure use. Descriptive stat istics for the quant itative component of the LOES-T are presented in Table 1.

Table 1. Description of Leaming Object Evaluation Scale for Teachers (LOES-T)

\begin{tabular}{|l|r|c|c|c|l|}
\hline Construct & \multicolumn{1}{|l|}{$\begin{array}{l}\text { No. } \\
\text { Items }\end{array}$} & $\begin{array}{c}\text { Possible } \\
\text { Range }\end{array}$ & $\begin{array}{c}\text { Actual Range } \\
\text { O bse rved }\end{array}$ & Me an (S.D) & $\begin{array}{l}\text { In te mal } \\
\text { Reliability }\end{array}$ \\
\hline LOES-T & 2 & 2 to 14 & 6 to 14 & $11.6(1.7)$ & $r=0.63$ \\
Learn & 3 & 3 to 21 & 11 to 21 & $17.7(2.8)$ & $r=0.69$ \\
Usability & 3 & 2 to 21 & 9 to 21 & $17.3(2.4)$ & $r=0.84$ \\
Engage & &
\end{tabular}


The internal reliability estimates for the LOES-T constructs were 0.63 (Learning), 0.69 (Usability), and 0.84 (Engagement) - see Table 1. The engagement construct showed good reliability, but the learning and usability constructs demonstrated relatively low reliability (Kline, 1999; Nunnally, 1978).

A principal components analysis was done to explore whether the three WBLT constructs (learning, usability, and engagement) in the LOES-T formed three distinct factors. Since all communalities were above 0.4 (Stevens, 1992), the principal component analysis was deemed an appropriate exploratory method (Guadagnoli \& Velicer, 1988). Orthogonal (varimax) and oblique (direct oblimin) rotations were used, given that the correlation among potential strat egy combinations was unknown. These rotational methods produced identical factor combinat ions, so the results from the varimax rotation (using Kaiser normalization) are presented because they simplify the interpretation of the data (Field, 2005). The Kaiser-Meyer-Olkin measure of sampling adequacy $(0.750)$ and Bart lett's test of sphericity $(p<.001)$ indicated that the sample size was acceptable.

Table 2. Varimax Rotated Factor Loadings on Teacher Learning Object Evaluation Scale

\begin{tabular}{|l|c|c|c|}
\hline Scale Item & Factor 1 & Factor 2 & Factor 3 \\
\hline T-Leam 1 - Graphics & .875 & & \\
\hline T-Learn 2 - Students Learn & .694 & & \\
\hline & & & \\
\hline T-Usability 3 - Easy to Use & & .795 & \\
\hline T- Usability 4- Easy to Learn & & .794 & \\
\hline T- Usability 5 - Instructions & & .570 & \\
\hline & & & \\
\hline T-Engagement 6 - Interact & .629 & & .558 \\
\hline T-Engagement 7 - On Task & & & .932 \\
\hline T-Engagement 8 - Motivated & & & .741 \\
\hline & & & \\
\hline FAC TOR & EIG ENVALUE & PC TOF VAR & C UM PC T \\
\hline 1 & 3.79 & 47.4 & 47.4 \\
\hline 2 & 1.38 & 17.3 & 64.6 \\
\hline 3 & 0.73 & 9.2 & 73.8 \\
\hline
\end{tabular}

The principal components analysis was set to extract three factors (Table 2). The resulting rotation corresponded well with the proposed WBLT evaluation constructs with one exception. Scale it em six, referring to students "liking to interact" with the WBLT showed a high value for both learning and engagement constructs. Overall, the structure was consistent with previous research (Kay \& Knaack, 2005, 2007b, in press) and the proposed grouping of scale items listed in Appendix B.

Correlations among the three LOES-T constructs (learning, usability, and engagement) were significant, but also small enough to support the assumption that each construct measured was distinct (T able 3 ). 
Kay, Knaack, \& Petrarca

Table 3. Correlations among Te acher Learning Object Evaluation Scale Constructs

\begin{tabular}{|l|c|c|c|}
\hline & T-Learn & T-Usability & T- Engagement \\
\hline T-Learn & 1.00 & $0.59 * *$ & $0.52 * *$ \\
\hline T- Usability & & 1.00 & $0.39 *$ \\
\hline T-Engagement & & & 1.00 \\
\hline$* \quad p<.005$ (2-tailed) \\
$* * \quad p<.001$ (2-tailed)
\end{tabular}

\section{Student survey}

After using a WBLT, students completed the Learning Object Evaluation Scale for Students (LOES-S) to determine their perceptions of (a) how much they leamed (learning construct), (b) the usability of the WBLT (usability construct), and (c) how much they were engaged with the WBLT (engagement construct). Selection of these constructs was based on a detailed review of the WBLT literature over the past 10 years (Kay \& Knaack, 2007b). The scale showed good reliability ( 0.78 to 0.89 ), face validity, construct validity, convergent validity, and predictive validity.

\section{Student performance}

Students completed a pre- and post-test created by each teacher based on the content of the WBLT used in class. Questions for pre- and post-test were identical in form, but differed in the raw numbers used. The type of questions asked varied according to the goal of the specific WBLT. Some tests focussed primarily on factual knowledge while others focussed on higher order thinking involving "what-if" scenarios. The measure was used to determine student performance. Because of the wide range of WBLT s used, it was not possible to assess the validity of this test data.

\section{Data Analysis}

First, the context of WBLT use was analysed by asking teacher a series of descriptive questions about how long it took them to find and integrate WBLT s into their classroom, their purpose for using the WBLT and strat egies they used to int egrate WBLTs. Next, the following analyses were run to examine teacher perceptions of the use of WBLT s in the classroom:

1) a descriptive overview of students learning, usability, and engagement as perceived by the teachers;

2) correlation between teachers and student analysis of WBLT s; and

3) correlation between teacher perceptions of learning, usability and engagement with student performance.

Finally, teacher comments were summarized for overall learning (Question 9 - Appendix B), technological issues (Question 10 - Appendix B), and suggestions for fut ure use (Question 11 to 12 - Appendix B). 


\section{Results}

\section{Use of WBLTs}

\section{Finding a WBLT}

Forty-one percent $(n=26)$ of the teachers reported that finding locating an appropriate WBLT took less than 30 minutes. Thirty-eight percent $(n=24)$ took 30 to 60 minutes and the remaining $22 \%$ $(n=14)$ took over an hour.

\section{Preparing a WBLT lesson}

Length of time to prepare a lesson to incorporate the WBLT varied. Eight percent of the teachers $(n=5)$ spent little or no time, $41 \%(n=26)$ spent less than 30 minutes, $30 \%(n=19)$ spent 30 to 60 minutes, and the remaining $22 \%(\mathrm{n}=14)$ spent over an hour.

\section{Using a WBLT}

On average, teachers used WBLT s for 35.5 minutes (SD 27.9) with a range of 6 to 60 minutes. However, there was considerable variability (6 to 210 minutes). Students worked independently on individual computers in a majority of classrooms $(92 \%, \mathrm{n}=59)$, while a small group of students $(8 \%, \mathrm{n}=5)$ worked cooperatively with peers.

\section{Reason for using a WBLT}

The top four reasons cited by teachers for using WBLTs were to review a previous concept (53\%, $\mathrm{n}=34)$, to provide another way to examine a concept $(50 \%, \mathrm{n}=32)$, to motivate students about a topic $(44 \%, n=28)$, and to introduce a new topic $(30 \%, n=19)$. Teachers rarely used WBLT s to teach a new concept $(6 \%, n=9)$, to explore a new concept after a formal lesson $(5 \%, n=3)$, or for homework $(3 \%, n=2)$.

\section{Strategies for using WBLTs}

Many teachers in this study often briefly introduced the WBLT and then allowed the students to explore on their own $(61 \%, n=39)$. Only $17 \%$ of teachers $(n=11)$ offered a formal demonstration of the WBLT prior to student use. Thirty-two percent $(n=21)$ of teachers prepared a formal handout to guide students while they were using the WBLT. Finally, $38 \%$ of teachers $(n=25)$ engaged their students in a class discus sion afterthe WBLT was used.

\section{Descriptive Overview of Learning, Usability and Engage ment}

\section{Teachers}

Teachers gave high ratings to perceived student learning, usability, and student engagement. Average it em ratings (out of 7) ranged from 5.8 to 5.9 (see Table 1 for construct means). Over 78\% of all teachers agreed or strongly agreed that students learned effectively with WBLT s. Sixty-four percent agreed or strongly agreed that the WBLT s selected were easy to use, and 65\% agreed or strongly agreed that students were engaged while using the WBLTs.

\section{Students}

Average rat ings from students were lower than those given by teachers, ranging from 3.4 to 3.8 out of five (4.8 to 5.3 on a 7-point Likert scale). Student ratings were closer to neutral (3 on a 5point Likert scale) with respect to learning $(M=3.4 ; S . D .=0.9)$ and engagement $(M=3.4 ; S . D .=$ 
$0.8)$ and to agree (4 on a 5-point Likert scale) with respect to usability of the WBLT ( $M=3.8 ; S . D$. $=0.9)$. Compared to teachers, students selected agree or strongly agree far less for the learning (32\% vs. $78 \%$ ), usability ( $49 \%$ vs. $64 \%$ ), and engagement constructs (36\% vs. 65\%).

Correlation among Teacher and Student Perceptions of WBLTs All three constructs on the teacher scale (LOES-T) were significantly correlated with all three constructs on the student scale (LOES-S). Correlations were modest $(0.25$ to 0.47$)$ indicating a certain degree of consistency between student and teacher evaluations of WBLT s.

Table 4. Correlations among LOES-S and LOES-T Cons tructs

\begin{tabular}{|c|c|c|c|}
\hline & S-Le arn & S-Usability & S-Engagement \\
\hline T-Learn & $0.47 * * *$ & $0.47 * * *$ & $0.44 * * *$ \\
\hline T- Usability & $0.45 * * *$ & $0.45 * * *$ & $0.43 * * *$ \\
\hline T-Engagement & $0.25 *$ & $0.33 * *$ & $0.39 *$ \\
\hline$\overline{p<.0}$ & \multicolumn{3}{|c|}{$p<.05$ (2-tailed) } \\
\hline$p<.0$ & \multicolumn{3}{|c|}{$p<.01$ (2-tailed) } \\
\hline$p<.0$ & \multicolumn{3}{|c|}{$p<.001$ (2-tailed) } \\
\hline
\end{tabular}

\section{Correlation between Teacher Evaluations and Student Performance}

Learning performance (percent change from pre- to post-tests) for classes where a WBLT was not used for reviewing previously learned concepts $(n=19)$ was significantly and positively correlated with teachers' perceptions of student engagement $(r=.49 ; p<.05, \mathrm{n}=19)$, but not with perceptions of student learning $(r=.22 ; n . s ., n=19)$ or WBLT usability $(r=.36 ; n . s ., n=19)$ constructs. In other words, student performance was better when teachers perceived WBLT s as engaging.

\section{Teacher Comments}

\section{Overall Impact}

Four themes emerged from the 89 comments that teachers made about the overall impact of the WBLT : learning $(n=54,61 \%)$, engagement $(n=23,26 \%)$, time $(n=9,10 \%)$, and individual differences $(n=3,3 \%)$. Each of these areas will be presented in more detail.

\section{Learning}

Seventeen percent of the teachers made direct comments about how much students learned. A number of teachers $(\mathrm{n}=10)$ made positive comments about how much was learned or how students were on task:

"The students gained good insight into a new concept"

"Students had a much better background in the subject when it was introduced [using WBLT s]"

"All students were on task during the 90 minute lesson - Note it is usually only a 60 minute class!" 
Some teachers $(n=4)$ observed that the WBLT was not as successful as they had hoped:

“Although the WBLT did not improve as many students' initial understanding of equation solving as I had hoped, it was useful."

"They still had great difficulty distinguishing between vertical and horizontal stret ches and compressions."

"The method of explanation and some of the wording was different than our ... textbook"

Many teachers $(n=19)$ commented on the effectiveness of WBLT s to provide visual supports:

"[the] WBLT helped them gain a solid visual of what happens to a parabola as you change the numbers of the vertex form of a parabola."

"Students were able to see a visual of a concept new to them."

"I think it really helped the students to visualize ... the meaning of balancing equations."

A good number of teachers $(n=15)$ felt that the WBLT s worked as good reviewtools for their students:

"It helped review a topic that I had taught them last year in grade 11."

"This WBLT was a great interactive review of concepts learned in grade 6. It not only helped review concepts, but it also motivated students about probability (the topic of our new unit)."

"I am always reviewing balancing equations, and this WBLT provided [the] students with an interactive and immediate means to assess what they remembered."

Finally, a few teachers $(n=4)$ commented that the WBLT s provided good interactivity for the students.

"This WBLT was a great interactive review of concepts learned in grade 6."

\section{Engagement}

Over one quarter of teacher comments $(n=23)$ referred to engagement as a key impact of WBLTs. Students were more interested or motivated when using this tool:

"Students were more motivated."

"I think students seemed to enjoy using it"

"The WBLT helped to motivate students and get them excited about learning math"

\section{Time}

Some teachers $(n=9)$ mentioned that time was an issue, either in creating a good lesson plan with a WBLT, saving time, booking the right time to use a WBLT s, or not having enough time:

"The WBLT allowed me to take a much shorter time to teach to teach the concept" 
"I had only had one class prior to using the WBLT to introduce the concept to the class because of problems at the school in terms of booking computer time."

"I think the WBLT was helpful. However, due to the time constraints of using this lesson, the usefulness was limited as well."

\section{Individual differences}

Finally, threeteachers noted individual differences with respect to the impact of WBLT s.

"Some students seemed to work well, however, one student was finished in 5 minutes, whilst another was finished in 35 minutes"

"The WBLT was a good one, but only my strongest students were able to learn the concept using the WBLT and accompanying worksheets."

\section{Technological issues}

Forty-three percent of the teachers reported having no technical problems whatsoever. Four key issues emerged from those teachers who did report problems: access $(n=14,19 \%)$, speed of Internet connections $(n=10,14 \%)$, software $(n=9,13 \%)$, and hardware $(n=7,10 \%)$. The main access problems teachers experienced were booking time for students to access the school computer lab and having enough computers in the lab to service the full class.

"It was very difficult to get the class into a computer room during this time period."

"There were not enough working computers so that each student could have his/her own."

"I love using WBLT s but will continue to avoid the use of computers in the classroom until we have more access to better computers."

A couple of teachers found loading time to be an issue when using the WBLT s:

"The loading of the [WBLT] was slow"

"The students had to be very patient waiting for the program to upload."

Some of the soft ware problems included not having the correct version of Java or Flash to load a WBLT or the URL link to the WBLT being too complicated to type in quickly and accurat ely.

Finally, a few teachers experienced hardware problems in the form of old, slow computers, computers that froze or did not work, and equipment, such as headphones, not working.

"One of the four computers in my classroom broke down in the middle of when the students were using WBLT."

"The computers ... in the room I booked [did] not all work. The ones that [did] work [were] very slow.

\section{Suggestions for future use}

Four areas were emphasized by teachers when offering suggestions for the fut ure use of WBLT s: searching $(n=35)$, preparation $(n=22)$, testing $(n=15)$, and support materials $(n=15)$. With respect to searching for WBLT s, many teachers said it took a long time and requested a single, searchable database organized by subject area, concepts, and/or curriculum expectations: 
"I would prefer a central place where I can find WBLT s indexed by topic of instruction."

"A more streamlined method of finding WBLT s would help in greatly reducing the amount of time spent finding suitable WBLT s."

"Surfing the various websites is an area that requires a lot of time."

Regarding preparation, suggestions did not follow any consistent pattern. Key recommendations included the following:

1. Make sure you are well prepared - you need to think about supporting worksheets, key questions, and sequencing (5 comments);

2. Allow extra time for using the computers - it takes longer than you think (5 comments);

3. Give students a sheet with the web address of the WBLT to save time (2 comments);

4. If you cannot get a computer lab, WBLTs can work well for homework (2 comments);

5. Plan well ahead because it can be very hard to book computer time (2 comments);

6. Make sure not to leave the students on their own - teacher support and discussion after the using the WBLT is import ant (2 comments);

Almost one quarter of the teachers $(n=15,23 \%)$ warned that it was criticalto test the computers, peripherals (e.g., headphones and mice), Internet speed, and WBLT thoroughly before giving it to a class. Finally, some teachers noted that the support materials could take a lot of time to develop, so they thought that pre-designed lesson plans and worksheets should accompany WBLT s.

\section{Discussion}

The purpose of this study was to examine WBLT s from the perspective of the middle and secondary school classroom teacher. The following research questions were addressed:

1. How do middle and secondary school teachers use WBLT s?

2. What are middle and secondary school teachers' att it udes about WBLT s with respect to learning value, usability, and engagement?

3. How do middle and secondary teachers' perspectives of learning, usability, and engagement compare with students' perceptions of the same three constructs?

4. How do middle and secondary teachers' perspectives of learning, usability, and engagement correlate with student learning performance?

5. What challenges do middle and secondary school teachers experience when using WBLT s?

Before, discussing each of these research questions it is prudent to discuss the methodology and quality of the evaluation tools used in this study. One of the main premises of this paper was that previous methods used to evaluate WBLT s were limited and that a more systematic, reliable, and valid approach was needed. 
Kay, Knaack, \& Petrarca

\section{Method Used to Evaluate WBLTs}

A total of 44 WBLT s in seven different subject areas were evaluated by 33 teachers in 64 separate classrooms involving over 1100 students in grades fiveto 12 . There is little doubt that this was a large, relatively diverse sample. The LOES-T showed good construct (principal component analysis) and convergent validity (correlations with student comments) and moderate to low reliability. The qualitative component of the measure provided rich supplementary data that was consistent with the quant it ative data reported. The learning construct, which showed relatively low reliability, may require modification for fut ure research. Overall, the evaluation tools used in this study provided a reasonable foundation with which to assess the impact of WBLT s.

\section{Use of WBLTs}

In this study, the typical preparation time for using a WBLT for a single class ranged from 30 minutes to over two hours, with the average time at about one hour. This does not appear to be an unreasonable amount of preparation time and not one teacher noted that it was an issue of concern. There is some evidence, then, that WBLT s partially address the previously reported barrier of excessive time needed to use technology (Eifler, Greene, \& Carroll, 2001; Wepner et al., 2003).

The time spent using a WBLT in class ranged from six to 210 minutes with an average time of just over 35 minutes. It is unclear from the data, though, how amount of time spent using a WBLT is related to teacher perceptions of use or actual learning performance. The amount of time spent using a WBLT may be linked to the type of WBLT used, the pedagogical approach chosen by the teacher, and computer access time. Further research is needed to address the impact of time. For the current study, it would be safe to say the results are limited to a one-time, short-term exposure to WBLT s.

It is important to note that teachers were cautious when using WBLTs in this study. Almost $70 \%$ of the time they chose to use the WBLT to either address previously taught concepts or to increase student motivation. Using a WBLT to teach a new concept occurred in only one third of the classrooms. Teachers may have been reluctant to risk using a new and untest ed tool to teach new concepts. Therefore, perceptions of WBLT s may have been somewhat skewed by the relatively modest teaching goals set by middle and secondary school teachers.

Strategies used by teachers in this study tended to be somewhat loose and open-ended: brief instruction, open exploration, and limited class discussion. Less than one third of the teachers prepared a guiding set of questions or handout for student use. These strat egies appear somewhat consistent with the cautious goals teacher set for using WBLTs. If teachers are uncertain about the value of WBLT s, they may be unwilling or unable to develop elaborate strat egies for integrating WBLT s into lessons. It is unclear how choice of strategy affected teacher perceptions of WBLT use or student learning performance.

\section{Teacher Perceptions of WBLTs}

\section{Learning}

The majority of teachers in this study felt that WBLT s resulted in successful student learning. This data was corroborated by qualitative feedback where teachers indicated that WBLTs led to increased student learning, provided effective visual aids, or offered a helpful review of concepts. Finally, teacher assessment of learning was significantly correlated to student assessment of learning. These positive results are consistent with previous data supporting the use of WBLT s in elementary and secondary schools (Brush \& Saye, 2001; Kay \& Knaack, 2007a; Kong \& Kwok, 2005; Liu \& Bera, 2005; Lopez-Morteo \& Lopez, 2007; Nurmi \& Jaakkola, 2006). 


\section{Usability}

Almost two thirds of theteachers agreed that WBLT s were easy to use. This result is not surprising given that the teachers selected the WBLTs to be used in their own classrooms. However, teachers did have an opportunity to observe the usability of the WBLT by students prior to assigning a final rating. Furthermore, teacher ratings of WBLT usability were significantly correlated with student ratings. Finally, the fact that almost half of the teachers reported notechnical problems and very few teachers reported soft ware difficulties provides indirect support that the WBLT s functioned well.

\section{Engagement}

There was considerable evidence to suggest that engagement of a WBLT was an important component. According to the survey data, close to two thirds of the teachers felt that WBLT s engaged students. This result is also supported by teacher comments where over $25 \%$ of the teachers spont aneously wrote that students were very interested and motivated by WBLTs. Furthermore, teacher assessments of engagement were consistent with student assessments. Finally, higher teacher ratings of engagement were significantly correlated with increased student performance. Clearly, engagement is a characteristic strongly associated with successful use of WBLT s.

\section{Teachers perceptions and learning performance}

Teacher perception of engagement was the only construct significantly correlated with learning performance. In other words, if a teacher thought a WBLT was engaging, students achieved significantly higher gains from pre- to post-tests. However, teacher assessment of WBLT usability and learning potential were not significantly related to leaming performance. It is speculated that usability may be required, but not essential to promote learning. For example, a WBLT that requires a student to click and read a series of pages is easy to use, but may limit learning because of the excessive reading required. It is puzzling, though, that teacher perceptions of learning were not significantly correlated with actual learning performance. These preliminary results should be treated with caution given the small sample of classes $(n=19)$ evaluated.

\section{Challenges experienced while using WBLTs}

At least three key themes emerged from over 150 comments made by the teachers who used WBLT s in their classrooms. First, time was a critical element that surfaced in many forms: time taken to search for good WBLT s, timetaken to develop good lesson plans and support materials, and time taken to test WBLT s before they were used in class. Needing time to develop good handouts and guidance for students using WBLTs is consistent with the results observed by Brush $\&$ Saye (2001). Not one teacher mentioned time being a problem with respect to learning how to use WBLTs (usability), a finding that supports the notion that WBLTs are relatively easy to leam and use. Nonetheless, using WBLT s effectively takes time -typical estimates for both selecting objects and lesson plan preparation ranged from one to two hours.

A second theme, related totime, was the effort required to search for WBLTs. Over $40 \%$ of the teachers noted that this process was not only time consuming, but occasionally frustrating. Typical search times ranged from less than 30 minutes to an hour. Most noted that a single database, searchable by various fields including subject, concept/topic, and curriculum expectations would be helpful. Unfortunately, this type of database does not exist. One of the main benefits of WBLT $s$ is that they are readily available from numerous sources. Teachers accessed at least 10 different databases for the current study. This availability, though, comes at cost of losing precision where references to local curricula and content organization are missing. 
The final theme gleaned from teacher comments on WBLT use involved the influence of technology. Forty percent of the teachers reported no problems what soever, a good sign given the range of problems that can occur in any one lesson. However, almost $60 \%$ of the teachers did experience technological challenges. T wo of the key problems reported, insufficient access and hardware problems, were unrelated to WBLT s. Even though computer-to-student ratios have improved to 1:5 in many countries, meaningful access for some classroom teachers in the current study was lacking. One teacher articulated the complexities of computer access this way:

"I love using WBLT s but will continue to avoid the use of computers in the classroom until we have more access to better computers. I am very computer literate - taught it for 5 years - but using computers in regular classes where we have to book out inferior labs is just a huge frustration. While the board insists our student to computer ratio is above average, in reality it is not. They count single computers in classrooms and computers I can never access because they are designated to computer and business classes. So I am stuck with just two labs - one in a very distracting library where I cannot teach. The other is a good location. As you can imagine booking the good room is an issue. There is a third room but the computers don't work. That is the room I had to use."

T wo WBLT -specific problems included speed of Internet connection and not having the supporting web software needed to run the WBLT s. WBLT s are web-based and often include animation. If the speed of the Internet is slow, this can cause considerable frustration and interrupt the flow of the class. Only 10 teachers experienced this problem, but it is still an important issue that can influence successful use of WBLT s is the classroom. McCormick \& Li (2006) also observed Internet challenges in their work with WBLTs. A few teachers noted that the free soft ware needed to run certain WBLT s, either Java or Flash, was not loaded on the computers. This was a relatively small administrative problem, but one that needs to be double checked before a WBLT is used. Most boards can readily update software if given sufficient notice.

In summary, the literature suggests that many schools are technologically prepared to support the use of computers in the curriculum (Compton \& Harwood, 2003; McRobbie et al., 2000; Plante \& Beattie, 2004; US Department of Education, National Center for Education Stat istics, 2002), but even with easy to use, readily available, free WBLT s, significant access and hardware issues remain.

\section{Suggestions for Future Use}

The suggestions that teachers made for future use of computers focused squarely on time. Teachers advised new users of WBLT s to give themselves enough time to search for WBLTs, test the WBLT s, and prepare lesson plans and support materials. All three factors are critical for the successful use of WBLTs. While both teachers and students valued WBLT s, preparation for using them effectively takes time. In fact, many teachers asked that the search process be streamlined either in the form of a one stop, searchable database or a "top ten" list. In addition, a number of teachers would have liked more support materials.

\section{Suggestions for Educators}

The results from this study offer a number of practical suggestions for teachers who plan to use WBLT s in the K-12 classroom. First, according to both teachers and students, the WBLT s used in this study were effective, easy-to-use and engaging. However, finding good WBLT s and preparing effective support materials takes time. Engagement appears to be one important feat ure to note when selecting a WBLT. Third, technological barriers in the form of insufficient access and 
hardware problems may be addressed by booking labs well ahead of time and thorough testing of computers. Software problems are relatively uncommon, but may also be avoided by testing the WBLT on student computers before the class begins.

Finally, the issue of time is important when using WBLTs. It appears thetypical time needed to locate an appropriate WBLT and prepare an effective lesson is one to two hours. Incorporating WBLT s into a lesson takes extra time in the form of searching, test ing, and preparation. It should be noted, though, that not one teacher said the time spent was a significant problem. In fact, many teachers used WBLT s more than once in this study. As one educator noted, there are always trade-offs with respect to time:

"The time spent looking for an effective WBLT, and modifying it slightly, proves worthwhile with a lesson that pretty-much runs itself as the student interacts with engaging media."

\section{Caveats and Future Research}

This study was designed to be methodologically comprehensive. A WBLT evaluation tool for teachers was employed that was sensitive to key issues researched over the past ten years (Kay \& Knaack, 2005, 2007b, in press). This tool showed low to moderate reliability and good construct validity. Since little formal research has been done assessing teacher att it udes toward the use of learning objects, it would be wise to conduct fut ure studies in order to refine and improve the quality of assessment tools directed toward assessing teacher's att it ude toward the use of learning objects.

Strategies used with WBLT s probably have an impact on effectiveness. For example, a WBLT used exclusively as a motivational or demonstration tool might not have as much impact as a WBLT used to teach a new concept. An analysis of instructional strategies could offer additional understanding of how to use WBLT s more successfully.

Tests used to assess performance in this study were created on an ad hoc basis by individual teachers. This study did not attempt to standardize measures or to assess reliability and validity. Higher quality learning performance tools should increase the precision of results collected.

The WBLT s tested in this study focussed primarily on mathematics and science. Markedly different features may be important for other subject areas. Fut ure research should examine WBLT s in more diverse subject areas.

Classroom observations of the use of WBLT s were not conducted. The collection of this type of data would be valuable in assessing the reliability and validity of the results reported in the current study. In addition the sample size of 33 teachers and 64 classrooms is relatively small, even though over 1100 students were involved.

Finally, while there is evidence to suggest that interactivity, engagement, and usability are key features in selecting WBLT s, the results from this study do not indicate how these constructs interact with learning. Fut ure research might incorporate a cognitive task analysis to determine how each of these constructs contribut es to the learning process. For example, individual students could be asked to think-aloud while using a WBLT in order to gather a more profound understanding of how interactivity, engagement, and usability influence decision-making and performance.

\section{Summary}

The purpose of this study was to evaluate teachers' perceptions of WBLT s used in middle and secondary school classrooms. A moderately reliable, valid assessment tool was used that glean 
information about student learning, usability of WBLT, engagement, technological issues, and suggestions for future use. Overall, most teachers rated WBLT s as easy-to-use tools that engaged students and promoted successful learning. Teachers also noted searching for WBLT s and preparing lessons required significant time. Technological problems related to WBLT s were not reported often and focussed mostly on the speed of the Internet. The main suggestion offered by teachers was to be prepared to spend time selecting, testing, and preparing the materials in order to ensure successful use of WBLT s.

\section{References}

Adams, A., Lubega, J., Walmsley, S., \& Williams, S. (2004). The effectiven ess of assessment learning objects produced using pair programming. Electronic Journal of e-Learning, 2(2). Retrieved July 28, 2005 from http://www.ejel.org/volume-2/vol2-issue2/v2-i2-art1-adams.pdf

Agostinho, S., Bennett, S., Lockyer, L., \& Harper, B. (2004). Developing a learning object metadata application pro file based on LOM suitable for the Australian higher education market. Australasian Journal of Educational Technology, 20(2), 191-208.

Bartlett, A. (2002). Preparing preservice teachers to implement performance assessment and technology through electronic port folios. Action in Teacher Education, 24(1), 90-97.

Bradley, C., \& Boyle, T. (2004). The design, development, and use of multimedia learning objects. Journal of Educational Multimedia and Hypermedia, 13(4), 371-389.

Brush, T., Glazewski, K, Rutowski, K., Berg, K., Stromfors, C., Van-Nest, M., Stock, L., \& Sutton, J. (2003). Integrating technology in a field-bas ed teacher training program: The PT3@ASU project. Educational Technology, Research and Development, 51(1), 57-73.

Brush, T. \& Saye, J. (2001). The use of embedded scaffolds with hypermedia-supported student-centered learning. Journal of Educational Multimedia and Hypermedia, 10(4), 333-356.

Bullock, D. (2004). Moving from theory to practice: An examination of the factors that preservice teachers encounter as the attempt to gain experience teaching with technology during field placement experiences. Journal of Technology and Teacher Education, 12(2), 211-237.

Butson, R. (2003). Learning objects: Weapons of mass instruction. British Journal of Educational Technology, 34(5), 667-669.

Cochrane, T. (2005). Interactive QuickTime: Developing and evaluating multimedia learning objects to enhance both face-to-face and distance e-learning environments. Interdisciplinary Journal of Knowledge and Learning Objects, 1, 33-54. Retrieved August 3, 2005 from http://ijklo.org/Volume1/v1p033054Cochrane.pdf

Compton, V., \& Harwood, C. (2003). Enhancing technological practice: An assessment framework for technology education in New Zealand. International Journal of Technology and Design Education, 13 (1), 1-26.

Cuban, L. (2001). Oversold and underused: Computers in the classroom. Cambridge, MA: Harvard University Press.

Docherty, C., Hoy, D., Topp, H., \& Trinder, K. (2005). E-Learning techniques supporting problem based learning in clinical simulation. International Journal of Medical Informatics, 74(7-8), 527-533.

Doering, A., Hughes, J., \& Huffman, D. (2003). Preservice teachers: Are we thinking with technology? Journal of Research on Technology in Education, 35(3), 342-361.

Eiffer, K. Greene, T., \& Carroll, J. (2001). Walking the talk is tough: From a single technology course to infusion. The Educational Forum. 65(4), 366-375.

Field, A. (2005). Discovering Statistics Using SPSS (2nd ed.). Thousand Oaks, CA: Sage. 
Gadanidis, G., Gadanidis, J., \& Schindler, K. (2003). Factors mediating the use of online applets in the lesson planning of pre-service mathematics teachers. Journal of Computers in Mathematics and Science Teaching, 22(4), 323-344.

Guadagnoli, E., \& Velicer, W. (1988). On methods in the analysis of profile data. Psychometrika, 24, 95112.

Howard-Rose, D., \& Harrigan, K. (2003). CLOE learning impact studies lite: Evaluating learning objects in nine Ontario university courses. Retrieved July 3, 2007 from http://cloe.on.ca/documents/merlotconference10.doc

Ilomäki, L., Lakkala, M., \& Paavola, S. (2006). Case studies of learning objects used in school settings. Learning, Media, \& Technology, 31(3), 249-267.

Kay, R. H., \& Knaack, L. (2005). Developing learning objects for secondary school students: A multicomponent model. Interdisciplinary Journal of Knowledge and Learning Objects, 1, 229-254. Retrieved June 1, 2007 at http://iiklo.org/Volume1/v1p229-254Kay Knaack.pdf

Kay, R. H., \& Knaack, L. (2007a). A systematic evaluation of learning objects for secondary school students. Journal of Educational Technology Systems, 35(4), 411-448.

Kay, R. H., \& Knaack, L. (2007b). Evaluating the learning in learning objects. Open Learning, 22(1), 5-28.

Kay. R. H., \& Knaack, L. (in press). Assessing learning, quality and engagement in learning objects: The Learning object evaluation scale for students (LOES-S). ETR\&D.

Kay. R. H., Knaack, L., \& Muirhead, B. (in press). A formative analysis of instructional strategies for using learning objects. Journal of Interactive Learning Research, 20(4).

Kenny, R. F., Andrews, B. W., Vignola, M. V., Schilz, M. A., \& Covert, J. (1999). Towards guidelines for the design of interactive multimedia instruction: Fostering the reflective decision-making of preservice teach ers. Journal of Technology and Teacher Education, 7(1), 13-31.

Kline, P. (1999). The handbook of psychological testing (2nd ed.). London: Routledge.

Kong, S. C., \& Kwok, L. F. (2005). A cognitive tool for teaching the addition/subtraction of common fractions: A model of afford ances. Computers and Education, 45(2), 245-265.

Krauss, F., \& Ally, M. (2005). A study of the design and evaluation of a learning object and implications for content development. Interdisciplinary Journal of Knowledge and Learning Objects, 1. Retrieved June 1, 2007 from http://ijklo.org/Volume1/v1p001-022Krauss.pdf

Lopez-Morteo, G. \& Lopez, G. (2007). Computer support for learning mathematics: A learning environment based on recreational learning objects. Computers and Education, 48(4), 618-641.

Liu, M., \& Bera, S. (2005). An analysis of cognitive tool use patterns in a hypermedia learning environment. Educational Technology, Research and Development, 53(1), 5-21.

McCormick, R., \& Li, N. (2006). An evaluation of European learning objects in use. Learning, Media and Technology, 31(3), 213-231.

MacDonald, C. J., Stodel, E., Thompson, T. L., Muirhead, B., Hinton, C., Carson, B., et al. (2005). Addressing the eLearning contradiction: A collaborative approach for developing a conceptual framework learning object. Interdisciplinary Journal of Knowledge and Learning Objects, 1. Retrieved August 2, 2005 from http://ijklo.org/Volume1/v1p079-098McDonald.pdf

McRobbie, C. J., Ginns, I. S., \& Stein, S. J. (2000). Preservice primary teachers' thinking about technology and technology education. International Journal of Technology and Design Education, 10, 81-101.

McGreal, R. (2004). Learning objects: A practical definition. International Journal of Instructional Technology and Distance Learning, 1(9). Retrieved August 5, 2005 from http://www.itdl.org/Journal/Sep 04/article02.htm

Nunnally, J. C. (1978). Psychometric theory. New York: McGraw-Hill. 
Nurmi, S., \& Jaakkola, T. (2006). Effectiveness of learning objects in various instructional settings. Learning, Media, and Technology, 31(3), 233-247.

Parrish, P. E. (2004). The trouble with learning objects. Educational Technology Research \& Development, 52(1), 49-67.

Plante, J., \& Beattie, D. (2004). Education, skills, and learning - Research papers. Connectivity and ICT integration in Canadian elementary and secondary schools: First results from the Information and Communications Technologies in Schools Survey, 2003-2004. Statistics Canada. Retrieved Aug 29, 2004 from http://www.schoolnet.ca/home/documents/Report EN.pdf

Robertson, H. (2003). Toward a theory of negativity: Teacher education and information and communications technology. Journal of Teacher Education, 54(4), 280-296.

Russell, M., Bebell, D., O’ Dwyer, L., \& O’Connor, K. (2003). Examining teacher technology use: Implications for preservice and inservice teacher preparation. Journal of Teacher Education, 54(4), 297-310.

Schoner, V., Buzza, D., Harrigan, K. \& Strampel, K. (2005). Learning objects in use: 'Lite' assessment for fi eld studies. Journal of Online Learning and Teaching, 1(1), 1-18.

Stevens, J. P. (1992). Applied multivariate statistics for the social science applications (2nd ed.). Hillsdale, NJ: Erlbaum.

Strudler, N., Archambault, L., Bendixen, L., Anderson, D., \& Weiss, R. (2003). Project THREAD: Technology helping restructure educational access and delivery. Educational Technology Research and Development, 51(1), 39-54.

Thompson, A. D., Schmidt, D. A., \& Davis, N. E. (2003). Technology collaboratives for simultaneous renewal in teacher education. Educational Technology Research and Development, 51(1), 73-89.

U.S. Department of Education, National Center for Education Statistics (2002). Internet Access in U.S. Public Schools and Classrooms: 1994-2002. Retrieved August 30, 2004 from http://nces.ed.gov/programs/digest/d02/tables/dt419.asp

Vacik, H., Wolfslehner, B., Spork, J., \& Kortschak, E. (2006). The use of COCOON in teaching silviculture. Computers and Education, 47(3), 245-259.

Van Zele, E., Vandaele, P., Botteldooren, D., \& Lenaerts, J. (2003). Implementation and evaluation of a course concept based on reusable learning objects. Journal of Educational Computing and Research, 28(4), 355-372.

Vargo, J., Nesbit, J. C., Belfer, K., \& Archambault, A. (2002). Learning object evaluation: Computer mediated collaboration and inter-rater reliability. International Journal of Computers and Applications, 25(3), 1-8.

Waxman, H. C., Connell, M. L., \& Gray, J. (2002). A quantitative synthesis of recent research on the effects of teaching and learning with technology on student outcomes. Naperville, IL: North Central Regional Laboratory.

Wepner, S. B., Ziomek, N., \& Tao L. (2003). Three teacher educators' perspectives about the shiffing responsibilities of infusing technology into the curriculum. Action in Teacher Education, 24(4), 53-63.

Wiley, D. A. (2000). Connecting learning objects to instructional design theory: A definition, a metaphor, and a taxonomy. In D. A. Wiley (Ed.), The Instructional Use of Learning Objects: Online Version. Retrieved July, 1, 2005, from http://reusability.org/read/chapters/wiley.doc

Wiley, D., Waters, S., Dawson, D., Lambert, B., Barclay, M., \& Wade, D. (2004). Overcoming the limitations of learning objects. Journal of Educational Multimedia and Hypermedia, 13(4), 507-521. 


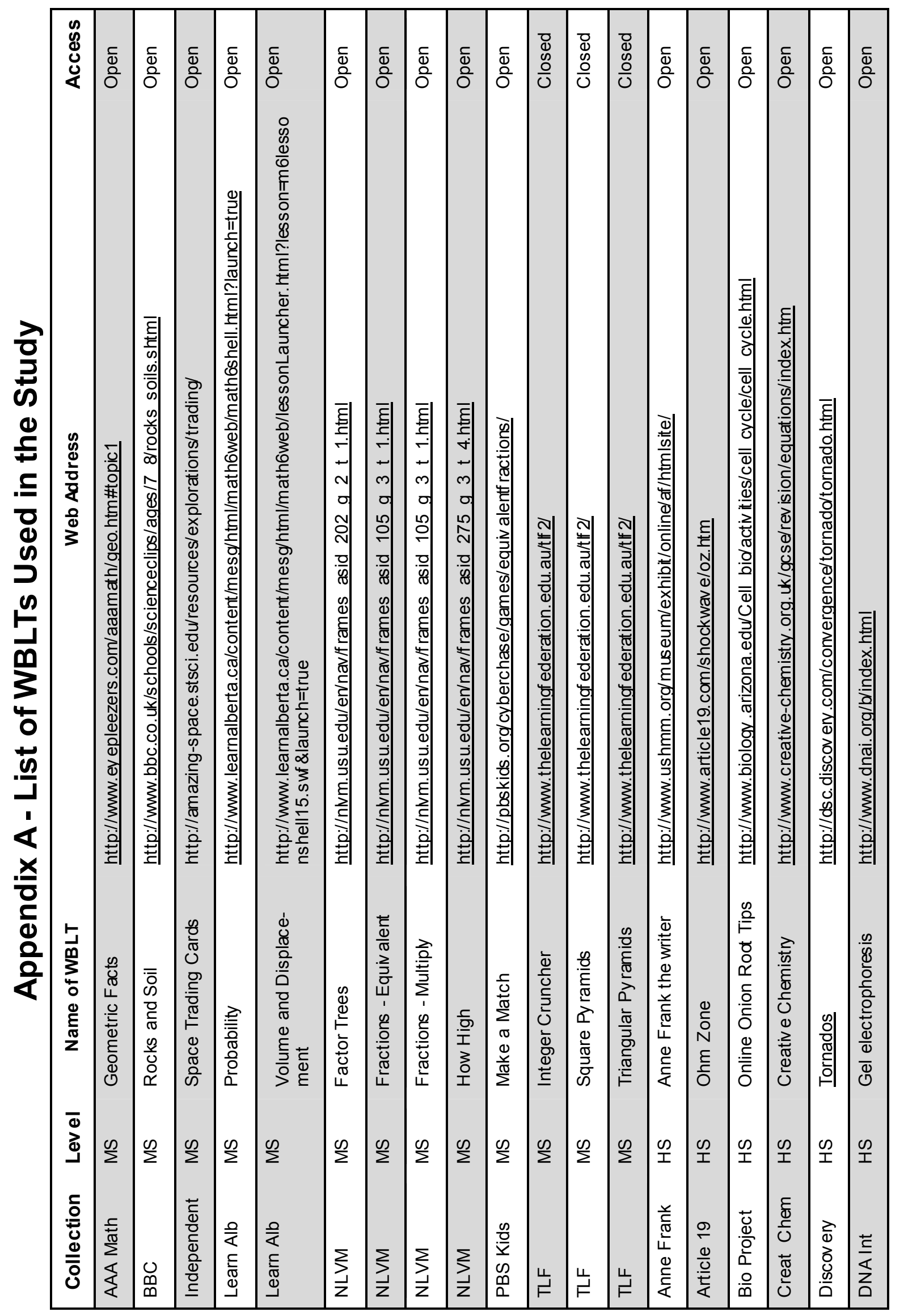




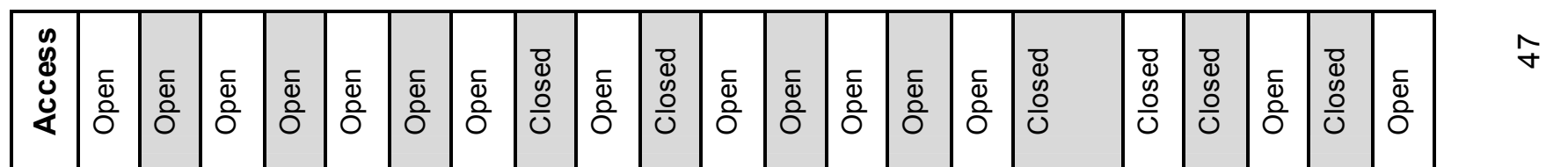

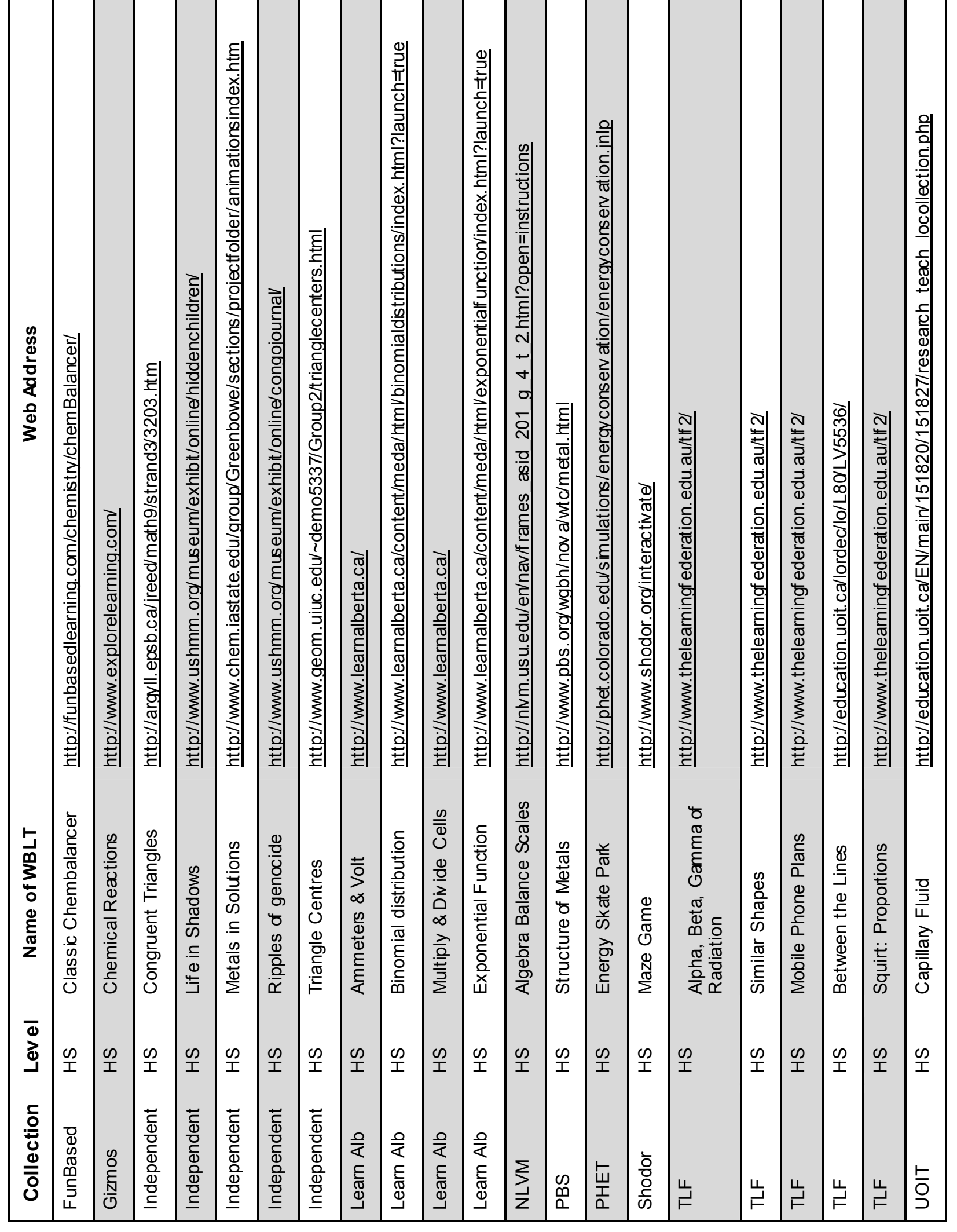




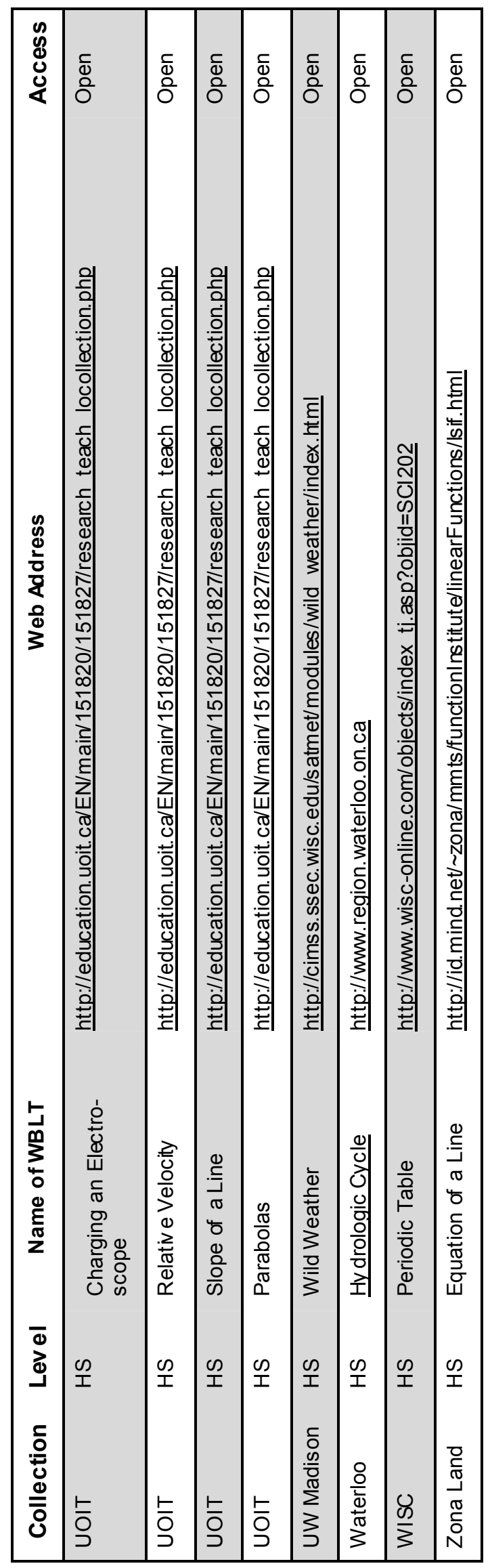




\section{Appendix B - \\ Learning Object Evaluation Scale for Teachers}

\begin{tabular}{|c|c|c|c|c|c|c|c|}
\hline & $\begin{array}{c}\text { Strongly } \\
\text { Disagree } \\
1\end{array}$ & $\begin{array}{l}\text { Disagree } \\
2\end{array}$ & $\begin{array}{c}\text { Slightly } \\
\text { Disagree } \\
\mathbf{3}\end{array}$ & $\begin{array}{c}\text { Neutral } \\
4\end{array}$ & $\begin{array}{c}\text { Slightly } \\
\text { Agree } \\
5\end{array}$ & $\underset{6}{\text { Agree }}$ & $\begin{array}{c}\text { Strongly } \\
\text { Agree } \\
7\end{array}$ \\
\hline \multicolumn{8}{|l|}{ Learning } \\
\hline $\begin{array}{l}\text { 1. The graphics and anima- } \\
\text { tions from the learning ob- } \\
\text { ject helped students learn. }\end{array}$ & 1 & 2 & 3 & 4 & 5 & 6 & 7 \\
\hline $\begin{array}{l}\text { 2. The students were able to } \\
\text { learn from the learning ob- } \\
\text { ject. }\end{array}$ & 1 & 2 & 3 & 4 & 5 & 6 & 7 \\
\hline \multicolumn{8}{|l|}{ Usability } \\
\hline $\begin{array}{l}\text { 3. The learning object was } \\
\text { easy for students to use. }\end{array}$ & 1 & 2 & 3 & 4 & 5 & 6 & 7 \\
\hline $\begin{array}{l}\text { 4. The learning object was } \\
\text { easy to learn. }\end{array}$ & 1 & 2 & 3 & 4 & 5 & 6 & 7 \\
\hline $\begin{array}{l}\text { 5. The students found the } \\
\text { learning object instructions } \\
\text { clear }\end{array}$ & 1 & 2 & 3 & 4 & 5 & 6 & 7 \\
\hline \multicolumn{8}{|l|}{ Engagement } \\
\hline $\begin{array}{l}\text { 6. The students liked interact- } \\
\text { ing with the learning ob- } \\
\text { ject. }\end{array}$ & 1 & 2 & 3 & 4 & 5 & 6 & 7 \\
\hline $\begin{array}{l}\text { 7. The students were on task } \\
\text { while using the learning } \\
\text { object. }\end{array}$ & 1 & 2 & 3 & 4 & 5 & 6 & 7 \\
\hline $\begin{array}{l}\text { 8. Students were motivated } \\
\text { while using the learning } \\
\text { object. }\end{array}$ & 1 & 2 & 3 & 4 & 5 & 6 & 7 \\
\hline
\end{tabular}

\section{Overall Impact on Learning}

9. What was the overall impact of the learning object on your lesson?

\section{Technological Problems}

10. Were there any technology-based problems that you encountered while using your learning object. Please explain.

\section{Suggestions for Future Use}

11. What information would you like to have in order to use learning objects more effectively in the future? Please explain.

12. What advice would you give to future teachers about using learning objects in their lessons? 


\section{Biographies}

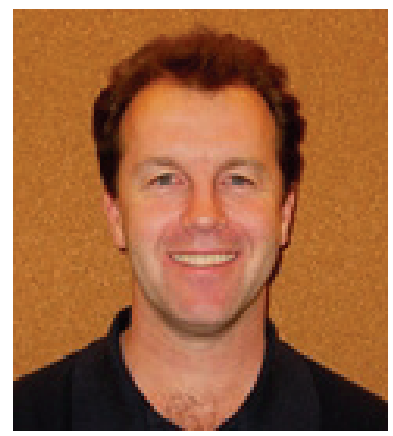

Robin Kay, Ph.D. is an Associate Professor in the Faculty of Education at the University of Ontario Institute of Technology. He has published over 40 articles in the area of computers in education, presented numerous papers at 10 int ernational conferences, refereed three prominent computer education journals, and taught computers, mathematics, and technology for over 18 years. Current projects include research on lapt op use in teacher education, discussion board use, electronic evaluation of teacher education programs, and factors that influence how students learn with technology.

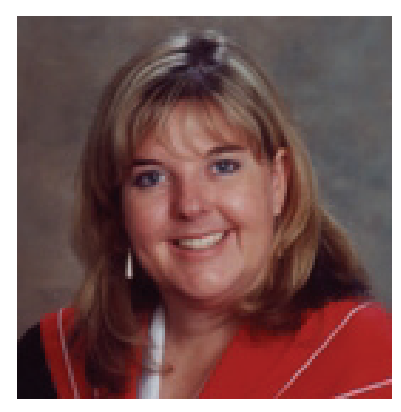

Lie sel Knaack, Ph.D. is an Assistant Professor in the Faculty of Education at the University of Ontario Institute of Technology. Her research interests are in the areas of design, development and evaluation of learning objects, effective integration of computers in the curricula, instructional design of digital learning environments and the process of change in implementing technology use at institutions of higher education. Current projects include laptop use in preservice education programs, online discussions, and digital performance appraisals.

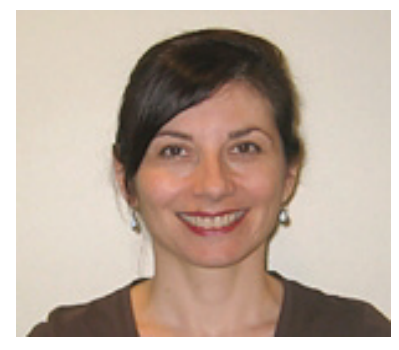

Diana Petrarca, M.A. is a Ph.D. graduate student at the University of Calgary and an instructor in the Faculty of Education at the University of Ontario Institute of Technology. Her current research focus is on the use of leaming-objects to support the supervision of pre-service teachers. 